\title{
Rehabilitation and Reintroduction of wild born orphan chimpanzee (Pan troglodytes) within the pongo and okokong islands of the douala-edea wildlife reserve, Littoral Region Cameroon
}

\author{
Tsi Evaristus Angwafo ${ }^{1}$, Atanga Roland ${ }^{2}$, Valentine Buh Ebua ${ }^{1}$ \\ ${ }^{1}$ Department of Fundamental Sciences, Higher Technical Teacher Traning College (HTTTC) Bambili, P O Box 39 Bambili, The \\ University of Bamenda - Cameroon \\ ${ }^{2}$ Department of Forestry, Faculty of Agronomy and Agricultural Sciences (FASA), University of Dschang - Cameroon
}

\begin{abstract}
This study had as main objective to document on the reintroduction of chimpanzees in the Douala-Edea Wildlife Reserve which appears to be the first case of chimpanzee reintroduction in Cameroon. The study was carried out in the South East zone of the Douala-Edea Wildlife Reserve which holds a small chimpanzee sanctuary under the auspices of "Papaye France" association. Data was collected on the field using semi structured questionnaires, interviews and direct observations alongside a participatory action approach at the sanctuary. Data from discussion guide and questionnaires were descriptively analysed and discussed with respect to our objectives. There were 24 orphan chimpanzees all together present in the zone and being cared for by the association PAPAYE France. This association has released 16 chimpanzees on two Islands of the reserve, the first group made of 9 chimpanzees ( 6 males and 3 females) were released in 2008 on the Pongo Island and a second group made of 6 chimpanzees (4 males and 2 females) were released on the Okokong Island in 2010; one female was later introduced to this group early 2015. These chimpanzees were released after a rehabilitation process not in line with IUCN guidelines for reintroduction of great apes and not following any developed scientific approach or methodology. Despite this, the released chimps are faring well as new births have been recorded on either Islands, chimps feed, nest, movement and vocalize indicating there have gotten adapted to live on the Islands. It was also noted that the sizes of these islands may not maintain a viable, nutritionally self-sustaining population in the long run hence could better serve as a semi naturalistic sanctuary. It is necessary that the carrying capacities of the islands be determined while larger
\end{abstract}

potential release sites be assessed and prepared for an eventual transfer/reintroduction of these apes in the future.

Keywords- Rehabilitation, reintroduction, orphan chimpanzee, Pongo and Okokong Islands, Douala-Edea Wildlife Reserve.

\section{INTRODUCTION}

The common chimpanzee (Pan troglodytes), listed as Endangered on the IUCN Red List since 1996 andin CITES Appendix I prohibiting any form of international trade (UNEP-WCMC 2011), is threatened in Cameroon by habitat loss as a result of resource extraction and land conversion, as well as illegal hunting, pet trade, and disease (Oates et al. 2008). The cumulative world population of chimpanzees has declined by more than $66 \%$ over the past 40 years passing from 600,000 to less than 200,000 individuals (Butynski, 2001; Kormos et al., 2003) and on the other hand, some researchers have estimated that an $80 \%$ reduction is likely to occur over the next thirty-three years and this will leave the chimpanzee as "critically endangered" (Walsh et al. 2003). To protect chimpanzees from extinction we must address the root causes of numerous threats, including habitat loss, the illegal bushmeat exploitation and the exotic pet trade, armed conflict, and infectious disease; and also provide long lasting solutions of surveillance protection by Park Rangers or Ecological guards in our protected areas.

There is a continual growth in the number of "chimpanzee orphans" especially from the bushmeat trade as commercial bushmeat hunters (poachers) kill many chimpanzees every year. Infants, too small to be killed for meat, are often put on the "black market" for sale as pets or entertainers. The illegal trade of baby chimpanzees has become a source of 
significant mortality in wild population not only for the collection of babies but also because the capture of a baby is usually done after the mother and other group members have been killed. For each sale of a young chimpanzee, it is estimated that between 10 and 29 others have perished during the process of capture or transportation (Carter 2003). It can therefore be estimated that the pet trade has potentially affected as much as $7-20 \%$ of the wild population in recent years, assuming a total wild population size of 150,000 , which is the lower limit reported by Butynski(2001).

Currently, chimpanzees face local extinctions in areas previously considered to be their last strongholds (Walsh et al., 2003; Campbell et al., 2008; Greengrass, 2009). Given the severity of threats to wild populations, a diverse range of conservation approaches should be considered. Chimpanzee sanctuaries and Reintroduction of chimpanzees from captivity is one strategy to help restore dwindling wild populations (Goossens et al., 2005; Beck et al., 2007).

The IUCN African Primate Action Plan does not currently recommend reintroduction as a conservation action plan for any primate species (Oates, 1996). But in recognition of the potentially important role of release efforts from captivity for the conservation of chimpanzees and other great apes, the International Union for the Conservation of Nature (IUCN) reintroduction specialist group of the species survival commission (IUCN-SSC/RSG) has elaborated and published specific guidelines for reintroductions of great apes (Soorae and Baker, 2002; Beck et al., 2007). Reintroductions typically refer to attempts to re-establish a species within its historic range, in an area where it is locally extinct (Soorae and Baker, 2002; Beck et al., 2007). Reintroduction addresses conservation on two different levels. First, animals that are kept illegally as pets are rescued, rehabilitated, and then returned to the wild; and secondly, by reintroducing animals into areas where they are locally extinct, the wild populations are supplemented and potentially more forest can be protected (Cheyne, 2006).

The government of Cameroon seems to opt for these two levels of conservation as in the Douala-Edea wildlife reserve, is an association named Papaye France that runs a small sanctuary caring for orphan chimpanzees. The main goal of this association is to contribute to the conservation of chimpanzees by collecting, rehabilitating young chimps and releasing them into natural habitats where they strive to survive with greater independence though still under strict control and care. This association has attempted to rehabilitate and release some chimpanzees on two Islands in the reserve. This study therefore aims at characterizing the population of released chimpanzees; describing their rehabilitation and reintroduction process; and other management activities of the chimps while pointing out the major problems and opportunities presented in the management of these chimps.

\section{METHODOLOGY}

\section{Study area}

This study was carried out in the Douala-Edea wildlife reserve which is located in the Coastal area of the Littoral Region; in the Sanaga Maritime Division where it covers part of the Edea 1 subdivision, Mouanko subdivision and the Wouri Division where it covers part of Manoka subdivision. Its geographic coordinates lie between latitude $3^{\circ} 14^{\prime}$ and $3^{\circ} 53^{\prime} \mathrm{N}$ and longitude $9^{\circ} 34^{\prime}$ and $10^{\circ} 03^{\prime} \mathrm{E}$ of the Greenwich meridian. It has an area of about $1,600 \mathrm{~km}^{2}$ (160,000 ha). Its limits extend from the Atlantic coast for a distance of $35 \mathrm{~km}$ inland, with its Eastern boundary along river Dipombé, bounded in the West by the Atlantic Ocean, in the North by river Wouri and in the South by the Nyong River (Nzooh et al., 2005).

The reserve is characterized by a typical equatorial climate with average annual rainfall ranging from 3,000 to 4,000 $\mathrm{mm}$. The months of December and January are relatively dry (50mm of rain). Starting in February, rains become more abundant with a peak in June followed by a slight decline variable; a new peak in rainfall occurs from August to October. The monthly average temperature varies throughout the year from $24^{\circ} \mathrm{C}$ to $29^{\circ} \mathrm{C}$.

The reserve is located entirely within a sedimentary low plain, from 0 to $60 \mathrm{~m}$ (rarely up to $80 \mathrm{~m}$ ). This plain is crossed by rivers and swamps that provide the only relief to this very flat topography with major rivers being: River Sanaga, Kwakwa, Wouri, Lofe, Mvia and the largest surface water is Lake Tissongo. Also present are other smaller rivers, streams and creeks as well as part of the downward basin of River Dibamba falling into the Wouri estuary (ELF Serepca, 1987).

Like many sites in Cameroon, no systematic inventory of vertebrates has been done (WTG, 2008). However, the presence of a great variety of vegetation among which also extends marine waters provokes a great diversity of land and aquatic fauna. Primates/monkeys typical of the African forest are present in the area. These include: Putty-nosed Mangabey (Cercopitecus nictitans), Colobus monkey (Colobus satanas), Cercopitecus pogoniasgrayi. Chimpanzees (Pan troglodytes) and Forest Elephants (Loxodonta Africana cyclotis)are also present. Other species 
include Bush pig (Potamochoeruslarvatus), Forest antelope (Tragelaphus euryceros), Sitatunga (Tragelaphus spekii)and the highly threatened West African Manatee (Trichechus senegalensis)(Ajonina et al., 2005).

The vast extended waters of the estuaries, Sanaga River and Lake Tissongo provide habitats favorable to many bird species. This ecosystem has diversified population of birds estimated at more than 35 species divided into 22 families with protected species such as the winged duck (Pteronetta hartlaubii) and the African Gray Parrot (Psittacus erithacus) (Van der Waarde et al., 2007).

Over 135 fish species in 21 families with 21 endemics have been known from river Sanaga (Ticheler, 2000). Some of the fish species found in the Douala-Edea marine habitats include the Machoirons (Arius spp), Carp (Lutjanus endecanthus), Tilapia (Tilapia zilli) and Mackerel (Scomberromorus spp). Some of the reptile species found locally include: Crocodiles (Tylosurus crocodiles), Serpents
(Alligator spp), and the fresh water turtles and land tortoises (Testudinidae family) (CWCS, 1998; WTG, 2008).

\section{Choice of site}

The study was carried out in the South East zone of the Douala-Edea Wildlife Reserve (DEWR) which holds a small chimpanzee sanctuary under the auspices of "Papaye France" association (Figure 1). The association occupies two islands in which chimpanzees have been released and is based in a camp holding younger chimpanzees being prepared for release. The association uses Islands for this process because the chimpanzee movements are limited and access can easily be controlled for security purposes. This area was chosen so as to document on this chimpanzee release carried out by Papaye France which might be the first reintroduction to be realized in Cameroon. Therefore documenting this release process and evaluating its success may contribute to scientific knowledge on chimpanzee rehabilitation and reintroductions.

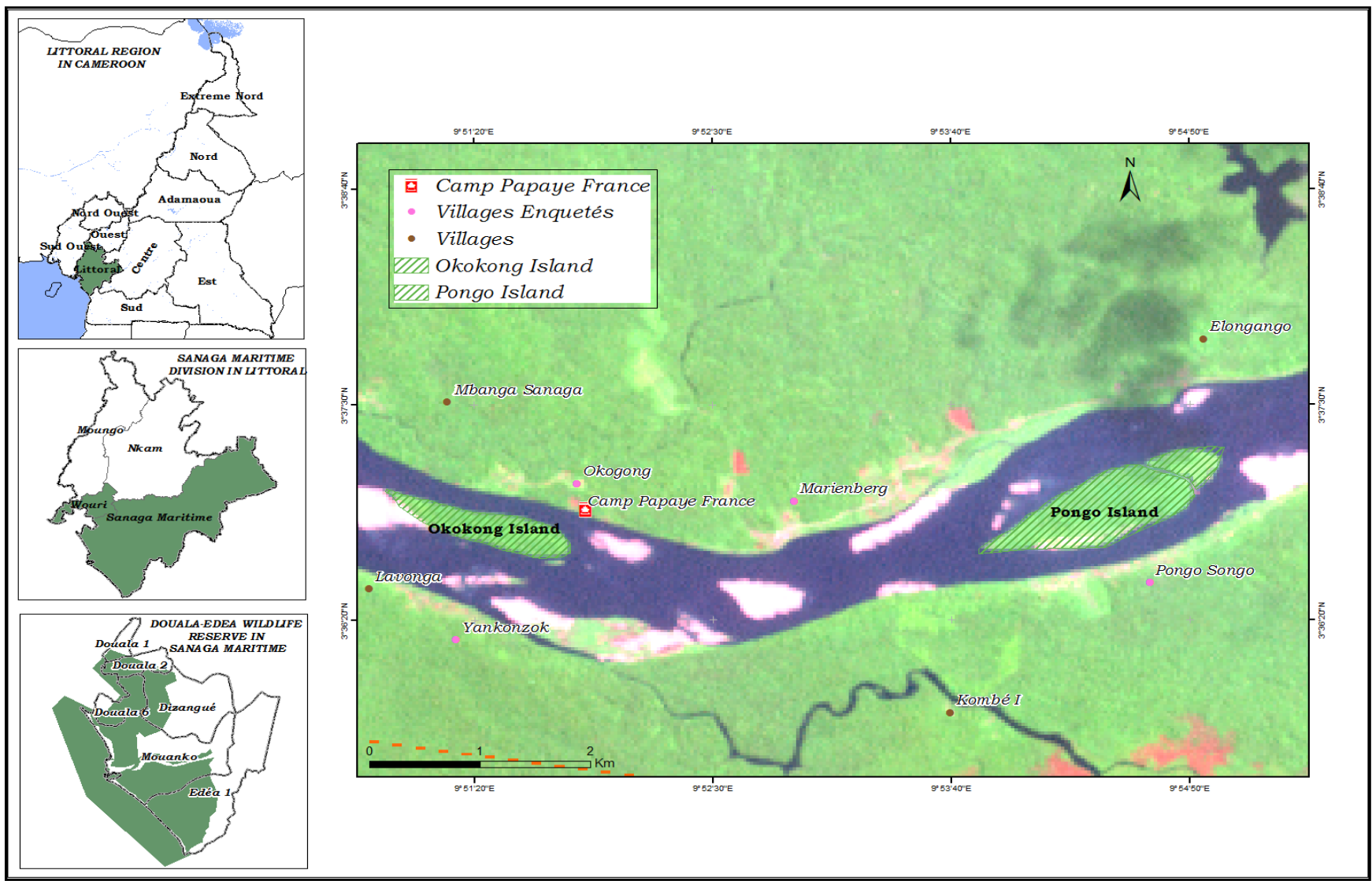

Fig.1: Map of Cameroon showing the location of Littoral Region and that of DEWR showing the two release sites (Pongo and Okokong islands) 
Data collection

Primary and secondary data were collected. Secondary data was gotten from past reports, scientific journals and other documents related to the study. Primary data were collected in the field using three main research instruments (interviews, direct observations and participatory action).

\section{Interviews}

Interviews were conducted with thepersonnel (manager and caregivers) of Papaye France working at the sanctuary and Forestry agents (Ministry of Forestry and Wildlife) at the conservation service of the reserve. Seven persons all together were interviewed; 4 personnel of Papaye France (manager and caregivers) and 3 forestry agents at the conservation service. These interviews were done with the help of a discussion guide drafted following the guidelines for chimpanzee and sanctuary management (Cox et al. 2000). These were conducted in order to get information on the management of the chimps and the sanctuary and also to characterize the population of orphan chimps being cared for.

\section{Direct observations and participatory action}

At the level of the rescue center of the association, information was obtained using a participatory approach (that is actively taking part in the daily activities which had to do with the care and follow up of the chimpanzees). This approach gave a better understanding of the management of the orphan chimpanzees, and the functioning of the association. Observations were done at the camp and on the islands. Following the recommendations of Cox et al 2000, observations were focused particularly on the important considerations for chimpanzee welfare (feeding regime of the chimps, the rehabilitation process undergone by the young chimps, the health and veterinary protocols and general management of the sanctuary). Also attention was drawn to the relationship between the sanctuary and the surrounding populations as well as human-chimpanzee interaction in the zone. A period of 3-4 days a week for a month was spent at the sanctuary observing and recording their daily activity budgets.

During these field observations, a GPS of mark GARMINE S60 was used to take geographic coordinates in the zone which permitted the mapping of the study area; and also the surface area of the Islands estimated. In order to estimate the area of the islands, a start point was chosen on one of the sides of the island and the coordinate noted. The tracklog option of the GPS was activated while going round the Island on an engine boat (staying as close as possible to the island) and coming back to the starting point. This exercise permitted a closed track whose area was automatically generated by the GPS.

\section{Data analysis}

Data from discussion guide were descriptively analysed using the statistical package for social science (SPSS) and discussed with respect to our objectives. Discussions were mainly comparisons and critics based on consulted literature.

Data gotten from the GPS was extracted using MAPSOURCE and transferred into ArcGIS10.0 software which was used to produce the map of the study area showing the Islands and also estimating their surface area.

\section{RESULTS}

Characterizing the orphan chimpanzee populations There are presently twenty four orphan chimpanzees being cared for and followed up by the association PAPAYE France. These chimpanzees are divided into three groups (Adult group on the Pongo Island, the adolescent group on the Okokong Island, and the babies or young chimps in the camp). The characteristics of these chimpanzees can be seen on table 1, 2 and 3 below.

Table.1: Characteristics of chimpanzees on the Pongo Island

\begin{tabular}{lllllll}
\hline $\begin{array}{l}\text { Identification of } \\
\text { chimpanzee }\end{array}$ & Sex & $\begin{array}{c}\text { Age/ } \\
\text { Years }\end{array}$ & $\begin{array}{c}\text { Date of } \\
\text { arrival in } \\
\text { camp }\end{array}$ & $\begin{array}{c}\text { Date of } \\
\text { release on } \\
\text { Island }\end{array}$ & Origin of chimpanzee & Observation \\
\hline Citron & M & 23 & 2003 & 2008 & South & Dominant male \\
Bambou & M & 21 & 2003 & 2008 & south & Died in February 2015 \\
Tony & M & 18 & 2003 & 2008 & $/$ & \\
Café & M & 19 & 2003 & 2008 & & Largest chimp \\
Charly & M & 23 & 2003 & 2008 & Kribi and its surroundings & \\
\hline
\end{tabular}




\begin{tabular}{|c|c|c|c|c|c|c|}
\hline $\begin{array}{l}\text { Identification of } \\
\text { chimpanzee }\end{array}$ & Sex & $\begin{array}{r}\text { Age/ } \\
\text { Years }\end{array}$ & $\begin{array}{c}\text { Date of } \\
\text { arrival in } \\
\text { camp }\end{array}$ & $\begin{array}{l}\text { Date of } \\
\text { release on } \\
\text { Island }\end{array}$ & Origin of chimpanzee & Observation \\
\hline Bobby & $\mathrm{M}$ & 22 & 2003 & 2008 & 1 & \\
\hline Samba & $\mathrm{F}$ & 23 & 2003 & 2008 & l & Nursing mother \\
\hline Wengue & $\mathrm{F}$ & 22 & 2003 & 2008 & l & Nursing mother \\
\hline Mangue & $\mathrm{F}$ & 23 & 2003 & 2008 & & Nursing mother \\
\hline Victoire & M & 6 & l & l & Born on the Island (2009) & Young of Mangue \\
\hline Pistache & M & 3 & I & I & Born on the Island (2012) & Young of Samba \\
\hline Passion & M & 2 & / & l & Born on the Island (2013) & Young of Wengue \\
\hline Cacaouette & M & 1.5 & l & l & Born on the Island (2014) & Young kid of Mangue \\
\hline
\end{tabular}

Table 1 shows that there were nine adult chimpanzees (6 males and 3 females) initially released on the Island in 2008. The chimps all came from the South Region of Cameroon (around Kribi, Djoum, Sangmelima and its surrounding localities where the association Papaye France started) indicating they belong to central chimpanzee subspecies $(P . t$. troglodytes). The chimpanzees arrived Pongo from Kribi in 2003 at an average age of 9.5years. These chimps were held in a camp and taken care of till 2008 when they were released on the Pongo Island at an average age of 14.5 years. All the three females released have put to birth with Mangue, one of the females having put to birth twice making 4 kids thus giving a total population of 13 chimps on the Pongo Island.

Unfortunately, one death has been registered on the Island. Bambou, one of the eldest males was lost in March 2015 due to an unpleasant incident of conflict with some villagers who severely injured the chimp with a machete.

Table.2: Characteristics of chimpanzees on the Okokong Island

\begin{tabular}{|c|c|c|c|c|c|c|}
\hline $\begin{array}{c}\text { Identification of } \\
\text { chimpanzee } \\
\text { (pseudo) }\end{array}$ & Sex & $\begin{array}{l}\text { Age/ } \\
\text { years }\end{array}$ & $\begin{array}{l}\text { Date of } \\
\text { arrival }\end{array}$ & $\begin{array}{c}\text { Date of } \\
\text { release on } \\
\text { Island }\end{array}$ & $\begin{array}{c}\text { Origin of } \\
\text { chimpanzee }\end{array}$ & observations \\
\hline Artimis & $\mathrm{F}$ & 14 & 2005 & 2010 & 1 & Breastfeeding \\
\hline Nénufar & $\mathrm{M}$ & 13 & 2004 & 2010 & l & Dominant male \\
\hline Etoile & $\mathrm{F}$ & 13 & 2004 & 2010 & I & \\
\hline Patchouli & M & 12 & 2005 & 2010 & l & \\
\hline Kiwi & M & 11 & 2006 & 2010 & I & \\
\hline Che Guevara & M & 11 & 2006 & 2010 & I & \\
\hline Kanel & F & 9 & 2007 & 2015 & I & \\
\hline Pomme & - & 4months & I & I & $\begin{array}{l}\text { Born on the island } \\
\text { (April 2015) }\end{array}$ & $\begin{array}{l}\text { Newly born to } \\
\text { Artimis }\end{array}$ \\
\hline
\end{tabular}

There are seven chimps ( 4 males and 3 females) on this Island of ages varying between nine and fourteen years plus a baby chimpanzee recently born to Artimis (the eldest female on the island). No records could be found on the acquisition of the chimps and their zones of origin which could be an indicator of the subspecies, thus it is possible to have two different subspecies (Pan troglodytestroglodytes and Pan troglodytes ellioti) cohabitating the island which could lead to the birth of a new hybrid. These chimps were released on the Island in 2010 after a rehabilitation period of 4-5years for most of the chimps.

Theyoungest chimps are found at the center where all new chimps are received and cared for before any subsequent release is envisaged. Table 3 below presents characteristics of the chimps present at the camp. 
Table.3: Characteristics of chimpanzees in the camp

\begin{tabular}{|c|c|c|c|c|}
\hline $\begin{array}{l}\text { Identification of } \\
\text { chimpanzee (pseudo) }\end{array}$ & Sex & Age & Origin of chimp & Date of arrival \\
\hline Miel & $\bar{F}$ & 8 & I & 2011 \\
\hline Banane & M & 3 & Douala & 2013 \\
\hline Guayave & $\mathrm{F}$ & 5 & I & 2012 \\
\hline Mandarine & $\mathrm{F}$ & 4 & Douala & 2014 \\
\hline
\end{tabular}

There are presently 4 young chimps at the camp, 1 male and 3 female. These chimps receive intense care and follow up by the caregivers preparing them for a subsequent release on one of the Islands.

\section{DISCUSSIONS}

\section{Description of the chimpanzee management}

The orphan chimps were either obtained from confiscations (law enforcement by MINFOF) or from donors. They are held in the camp where they receive care and undergo a rehabilitation process (without using the IUCN guidelines of 2010) helping them to socialize with other chimps and regain some natural aptitudes vital for their survival and wellbeing after which they are transferred to the Islands. The management of these chimps can be regrouped under three major aspects;

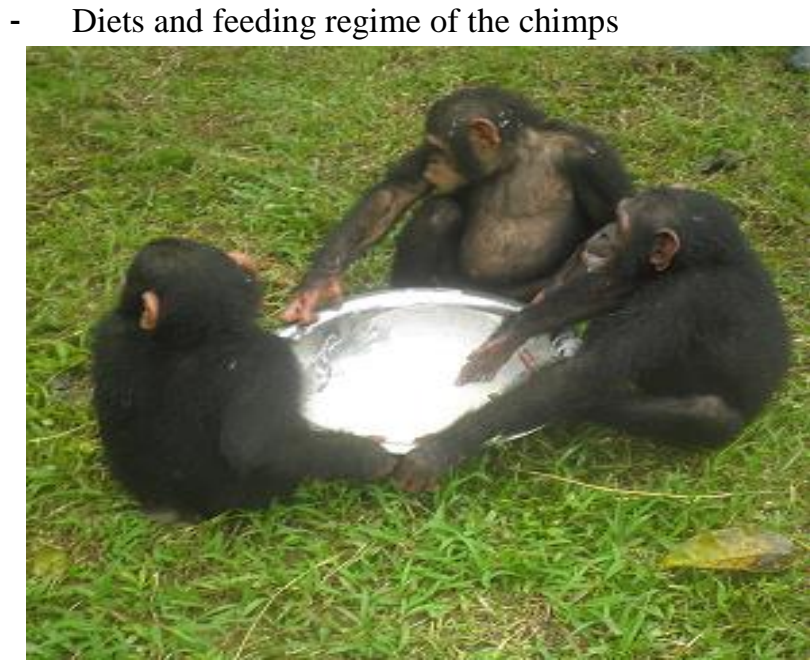

Fig.2 a and b: Young Chimps (in camp) feeding in a bowl of corn pap (Atanga Roland)
- The rehabilitation process proper and

- $\quad$ Their health care and hygiene

\section{Diet/Feeding regime}

The majority of the diet of the chimpanzees consists of fruits such as banana, pawpaw, pineapple, water melon and mango depending on their availability. Other food items also given to the chimps include sugar cane, coconuts, and occasionally fritters.

The young chimps at the camp are fed at least three times a day with varying diets. They are given food in the morning (6-9 am) usually bananas and other fruits butin case of fruit shortage, they are given cooked food (pap made of corn flour as shown on figure $2 \mathrm{a}$ and $\mathrm{b}$ below). In the afternoons around $1 \mathrm{pm}$, and evenings between 5 and $6 \mathrm{pm}$. There is no strictly respected feeding protocol for these chimps, as most of the time, they always have something chewing.

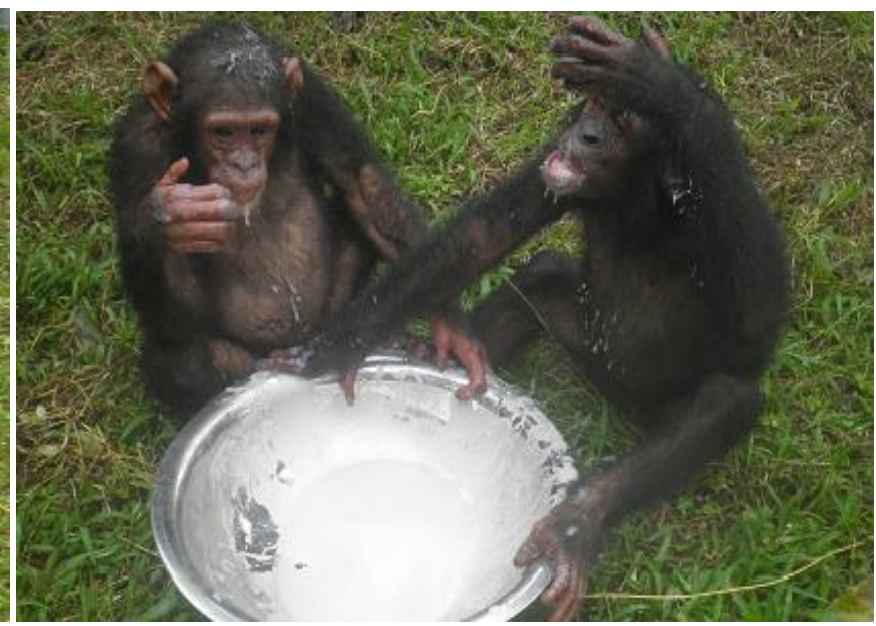

figs and cherry) and other foods on the Island based on the plant phenology during the fruiting season ( July to September). During this period, they are given less quantities of food as they complement their diet with wild fruits.

On the other side (the Pongo Island), the adult chimpanzees have achieved a greater level of independence as they are able to feed themselves and their young ones particularly 
during the fruiting season. As was noted by one of the caregivers, they also happen to hunt and kill monkeys that are found on the island to supplement their diet, a characteristic known to chimpanzees (Boesch et al. 2002). Although these chimps can get their own food, they are brought 2 baskets of fruits every two days and occasionally more when there are tourist visits. This exercise is simply a means of keeping a regular eye on the chimps, to make sure they are all faring well. Nevertheless these chimps demand greater attention during the dry season (between November and March) as the Island alone is not capable of meeting all their feeding requirements.
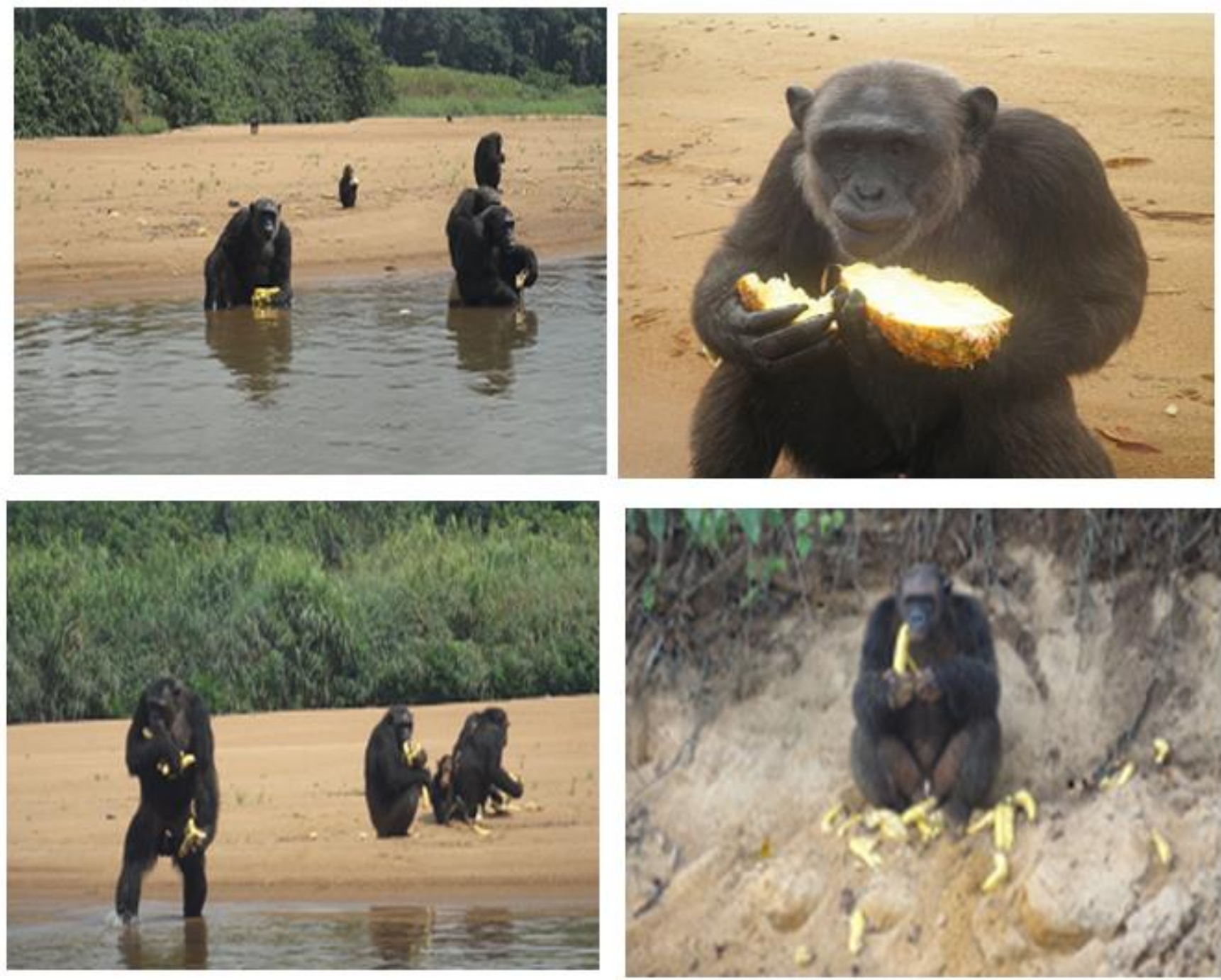

Fig.3: Chimpanzees feeding on the sandy shore or river bank (Atanga Roland)

\section{Rehabilitation and Reintroduction process}

The chimpanzees on the Pongo Island was the first group to be rehabilitated and released. They were brought to the Pongo village in 2003 where they were kept in a camp simulating their natural habitat and being taken care of. These chimpanzee were taken out on regular basis to the nearby forest as a daily exercise for them so they could play, brachiate, feed on wild foods and learn how to nest. This was the first stage in the rehabilitation of the chimps being done without any respected protocols. The Pongo
Island was then noticed offering a possibility for these chimps to be free, secured and far from human contact. An approval was gotten from the Minister in charge of Forestry and Wildlife to transfer these chimps on the Pongo Island who to an extent had already acquired certain natural aptitudes from their daily exercise in the forest. It was then that 9 of the chimps of ages between 12 and 16years were taken to the Islands in 2008. An enclosure was built for them where they stayed with their caregivers. These chimps strayed on the islands during the day and came back in the 
evenings to sleep in or around this enclosure, but within 6 months, none of the chimps came back to sleep in the enclosure as they began nesting and sleeping on trees. The enclosure was removed and the caregivers left the island only coming back during the day to observe the chimps and provision them with food and medicines. Within a year (that is in 2009), one of the females gave birth and presently 4 births have been registered on the island.

It was the same scenario with the chimpanzees on the Okokong Island, released 6 (4 males, 2 females) in 2010. One female was added to the group in 2015 and one birth was also registered within the same year. The rapid adaptation of these chimps to the islands and the level of independence reach is mainly due to the fact that all these were wild born and had passed sometime in the wild before being captured. This is in line with Ebua et al (2013) stipulating that captive wild-born primates fare well in rehabilitation and reintroduction programs as they easily acquire skills vital for their survival in the wild, captiveborn individuals.
The young chimps at the camp are submitted to a training or rehabilitation exercise on a daily basis. This exercise aims at helping the chimps acquire natural social and ecological skills that will permit them survive independently (or with greater independence) in the wild when weaned from human contact. They are taken out of their enclosures every morning (after feeding) between 7:30 and 8:30pm for a walk and training exercise in the nearby forest (Figure 4). The spend 3 to 4 hours in the forest, time during which the chimps jump from one tree to another, harvest wild fruits and certain leaves on which they feed, and play around with each other helping to strengthen social bonds between the chimps. This exercise takes place under the supervision and observation of the caregiver. Nevertheless the chimps do not face much difficulties getting acquainted with the natural milieu as they are all wild born chimps and had spent a few months or years with their parents before being captured. This confirms findings that nonhuman primates, wild born individuals fare well during rehabilitation than captive born individuals (Soorae et al., 2002; Ebua et al., 2013).

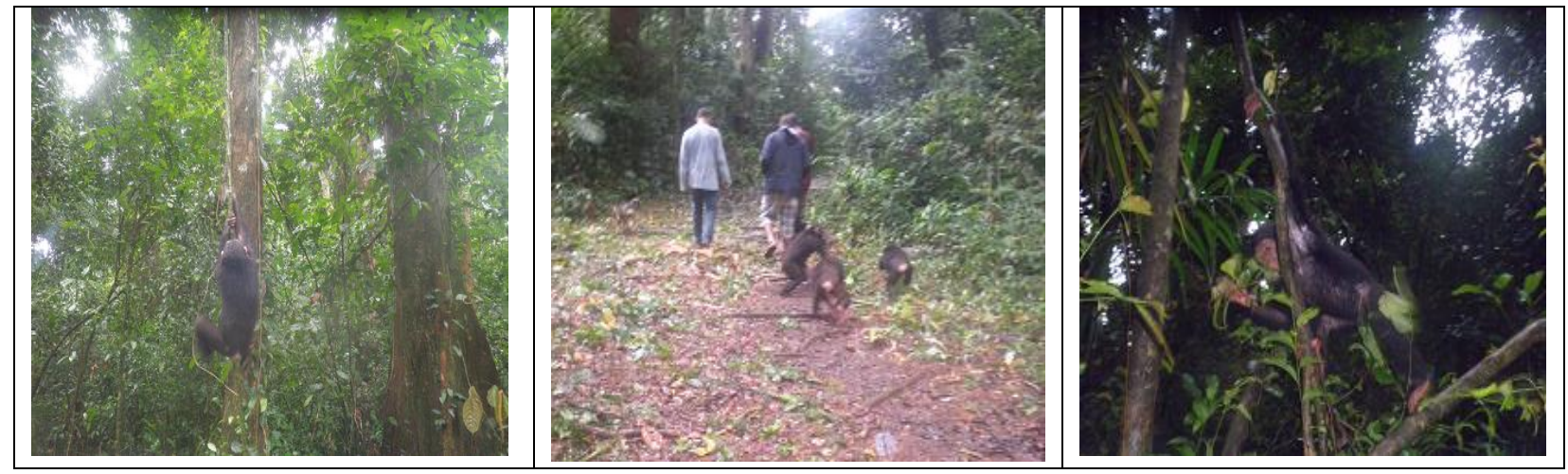

Fig.4: Young chimps taken out for rehabilitation in the forest (Atanga Roland)

\section{Health care management}

Many sanctuaries are established in relatively isolated areas with the result that wildlife veterinary and/or medical expertise is seldom easily accessible. For new chimps arriving the camp, there are first taken for checkup and examinations by a veterinary service present in the town of Edea before they can be brought to the camp. It is the same process for any chimp that falls sick or requires medical attention as there is no veterinary service or technician at the site. The chimpanzees are often given anti biotic mostly in the form of syrup mixed in their food or in water.

As for hygiene and cleaning of the chimp enclosure/cage, they are cleaned and disinfected twice a day.

\section{Research and tourism}

There are no developed research or education programs carried out by the association but researchers and volunteers are usually received for short periods of time usually varying between 2 weeks and 3 months. Research type accepted at the site is mostly observational and noninvasive research which may have little or no effect on the chimpanzee behavior. Tourism at the site is an important activity and a main source of fund raising for the care of the chimps and management of the sanctuary. Tourists are received throughout the year with most of them from European countries. An average of 7-8 tourists visit the area each week, this number about doubles on average during the dry season between the months of November and February.

Management problems 
- The sanctuary has no adequately trained personnel (wildlife specialist, no veterinary service, or someone with an educational background related to animal care) who could understand biological and ecological aspects of chimp behavior, keep records which could serve subsequent research or researchers and take management decisions which will ensure the long term welfare of the chimps.

- Chimpanzees in the wild are known to have a home range between 5 and $50 \mathrm{~km}^{2}$ in forest and woodland habitats (Nowak, 1999). The islands are of small sizes (92ha for Pongo and 46ha for Okokong) and can only support limited chimpanzee population sizes. No ecological habitat assessment has been carried out on the islands therefore its suitability as chimp habitat and carrying capacity is not known. But with respect to the IUCN guidelines for reintroduction of great apes stipulating that Islands less than 500ha with densities of more than 0.1 individual per ha cannot maintain a self-sustaining population (Becks et al., 2007). With this, the reproduction capacity of these chimps should be monitored and controlled less it extrapolates and exceeds carrying capacity of the Island.

- There are no developed management protocols drafted and followed for chimpanzee care, feeding, health care, tourist visits and research are done without any strictly respected guidelines or policies and is risky both to the chimps, the caregivers and others.

- One of the most difficult aspects of forming and running a sanctuary is the issue of funding. A realistic financial plan is a critical part of the sanctuary planning process. The management of the sanctuary and the chimps rests entirely in the hands of the promoter of the association and a few benevolent and volunteers. From verbal interview, the financial requirements of running the sanctuary are barely met indicating the need for developing adequate finance methods

\section{Management opportunities}

- $\quad$ The Islands of Okokong and Pongo could be better exploited to serve as a semi naturalistic sanctuary and a potential rehabilitation site rather than being considered as a permanent released site (as considered by Papaye France) because it cannot sustain viable populations of chimps in the long run. The area is well secured as it is found within a protected area which benefits from legal protection from the states hence security of the chimps and those working with is assured. Nevertheless an ecological habitat assessment must be carried out to know the suitability of these habitats and the maximum number of chimps they can sustain.

- The zone presents a good touristic potential which if coupled with the sanctuary will attract more tourists, therefore could be a significant source of income for the sanctuary management and to the local communities. Therefore ecotourism should be promoted as it could also be used as an opportunity to educate and raise awareness on the issues of conservation to a wide audience of people.

- Scientific research and education are opportunities presented by the sanctuary for studies and research programs on chimpanzees especially on behavioral aspects as the sanctuary provides an adequate milieu where these chimps can be observed for long periods of time. This could be exploited to better understand and document chimpanzee behavior, promote awareness, improve standards for chimp welfare and could also develop medical research.

\section{Weaknesses of the Rehabilitation and Reintroduction process by PAPAYE France}

- Firstly, it should be noted that, the rehabilitation and reintroduction of these chimpanzees was done with little or no apprehension of the IUCN guidelines for the reintroduction of great apes drafted in 2007 (Becks et al., 2007). It was done without much pre-release evaluation and with little post release monitoring. It is done without any scientific approach/methodology

- The camp and rehabilitation site did not respect the minimum distance of $22 \mathrm{~km}$ from the nearest human settlements, this so as to avoid cases of conflicts with local populations

- These individuals need to be exposed to a predatory awareness training because in captivity they tend to lose their natural talents of identifying and recognizing predators.

- There is need for a proper health and veterinary checks to avoid the retransmission of zoonotic infections and the risk of reintroducing individuals capable of surviving due to deformation, and improper ability to locomote. 


V. CONCLUSION

The released population of chimpanzees ( 9 on the Pongo Island and 7 on the Okokong Island) are all faring well as they are physically healthy. Four births have been registered on the Pongo Island from all released females while one birth had been registered on the Okokong Island. This being a sign of the welfare of these chimps on the Islands.

The rehabilitation and reintroduction process, though not carried out strictly according to recommended norms seems to be a success as they chimps are getting adapted on life on the Islands. They feed on wild fruits, easily nest, vocalize correctly and those on Pongo have even been noted hunting and killing monkeys which they eat. This adaptation is in part due to the fact that all the chimps were wild born and could easily develop aptitudes necessary for their survival; also the absence of natural predators on the island has contributed to this level of success. But knowing that the success of any reintroduction process can only be measured by the establishment of a nutritionally self-sufficient population (Beck et al., 2007), this reintroduction cannot yet be termed as successful as the feeding of the chimps is still supplemented. In other words, this release process could be a form of rehabilitation on a semi naturalistic sanctuary meanwhile it is recommended that potential release sites be assessed where these chimps may strive better and with greater independence; and a reintroduction be carried out following a well-developed scientific methodology.

Nevertheless chimpanzee management and care is quite a complex issue to deal with and for this reason sanctuaries are recommended to have written policies on all aspects of ongoing care and management of chimpanzees. Information on the chimpanzee behaviors should be recorded daily and kept as it could for serve subsequent research.

\section{ACKNOWLEDGEMENT}

We would like to thank the following for making this research a success: the Papaye France Association for accepting and collaborating to meet the objectives of the study; the Ministry of Forestry and Wildlife for initiating and providing the means for the realization of this study through the conservation service of the DEWR; the staff of the conservation service and Papaye France for their contribution to the study. We would like to thank our families for their relentless efforts and for supporting our absence throughout the study period.

\section{REFERENCES}

[1] Ajonina, PU; Ajonina,G.N ; Jin, E. Mekongo, F ; Ayissi. I. \& Usongo, L. (2005).Gender roles and economics of exploitation, processing and marketing of bivolves and impacts on forest ressources in the Douala- Edéa wildlife reserve, Cameroon. International journal of Sustainable Development and World Ecology 12 (2005):161-172.

[2] Beck, B., Walkup, K., Rodrigues, M., Unwin, S., Travis, D. and Stoinski, T., 2007. Best Practice Guidelines for the Re-introduction of Great Apes, IUCN/SSC Primate Specialist Group, Gland, Switzerland.

[3] Boesch C, Uehara S, \& Ihobe H. 2002. Variations in chimpanzee-red colobus interactions. In: Boesch C, Hohmann G, Marchant LF, editors. Behavioral diversity in chimpanzees and bonobos. Cambridge, England: Cambridge Univ Pr; p 221-30.

[4] Butynski, T.M., 2001. Africa's great apes. In: Beck, B.B., Stoinski, T.S., Hutchins, M., Maple, T.L., Norton, B., Rowan, A., Stevens, E.F., Arluke, A. (Eds.), Great Apes and Humans: The Ethics of Coexistence. Smithsonian Institution Press, Washington, DC, pp. 3-56.

[5] Campbell, G., Kuehl, H., N'Goran, K.P. \& Boesch, C., 2008. Alarming decline of West African chimpanzees in Cote d'Ivoire. Current Biology 18 (19), R903-R904.

[6] Carter, J. (2003). Orphan chimpanzees in West Africa: Experiences and prospects for viability in chimpanzee rehabilitation. In R. Kormos, C. Boesch, M. I. Bakarr, \& T. Butynski (Eds.), West African chimpanzees. Status survey and conservation action plan (pp. 157-168). Gland: IUCN/SSC Primate Specialist Group. IUCN.

[7] CWCS (Cameroon Wildlife Conservation Society). 1998. Annual Report Mouanko,Cameroon. 11pp.

[8] D. Cox, N. Rosen, C. Montgomery and U.S. Seal (Editors). Conservation Breeding Specialist Group (SSC/IUCN). 2000. Chimpanzee Sanctuary Guidelines and Management Workshop:Report. CBSG, Apple Valley, MN.

[9] Elf - Serepca 1987. Conclusions et recommandations du Groupe d'Interprétation Bassin de Douala. Rapport multi graphie 341-DE No. 6/160 ,Douala. 30 pp.

[10] Goossens, B., Setchell, J. M., Tchidongo, E., Dilambaka, E., Vidal, C. \& Ancrenaz, A. 2005. Survival, interactions with conspecifics and 
reproduction in 37 chimpanzees released into the wild.

Biological Conservation, 123(4), 461-475

[11] Greengrass, E.J., 2009. Chimpanzees are close to extinction in southwest Nigeria. Primate Conservation 24 (online 1-7).

[12] Kormos R., Boesch C., Bakarr M.I. \& Butynski T.M. (eds.) 2000. Chimpanzés d'Afrique del'Ouest: Etat de conservation de l'espèces et plan d'action. Groupe de Spécialistes des Primates, Commissionde la Sauvegarde des Espèces de l'UICN, Union International pour la Conservation de la Nature :http://www.primate-sg.org/PDF/WACAP.French.pdf last date of access 20/10/2015.

[13] Oates, J.F., Tutin, C.E.G., Humle, T., Wilson, M.L., Baillie, J.E.M., Balmforth, Z., Blom, A., Boesch, C., Cox, D., Davenport, T., Dunn, A., Dupain, J., Duvall, C., Ellis, C.M., Farmer, K.H., Gatti, S., Greengrass, E., Hart, J., Herbinger, I., Hicks, C., Hunt, K.D., Kamenya, S., Maisels, F., Mitani, J.C., Moore, J., Morgan, B.J., Morgan, D.B., Nakamura, M., Nixon, S., Plumptre, A.J., Reynolds, V., Stokes, E.J. \& Walsh, P.D. 2008.Pan troglodytes. In: IUCN 2011. IUCN Red List of Threatened Species. Version 2011.2. www.iucnredlist.org last date of access 20/10/2015

[14] Soorae, P. S. \& Baker, L. R. (eds.) 2002. Reintroduction NEWS: Special Primate Issue, Newsletter of the IUCN/SSC Re-introduction Specialist Group, Abu Dhabi, UAE. No. 21:60 pp. (ISSN: 1560-3709)

[15] UNEP-WCMC 2011. UNEP-WCMC Species Database: CITES-Listed Species

[16] Van der Waarde .J.J (Ed), 2007. Water bird census of coastal Cameroon and Sanaga River, January March 2007.WIWO Report No 83. Beek -Ubbergen.

[17] Walsh PD, Abernethy KA, Bermejo M, Beyers R, De Wachter P, Akou ME, Huijbregts B, Mambounga DI, Toham AK, Kilbourn AM, Lahm SA, Latour S, Maisels F, Mbina C, Mihindou Y, Obiang SN, Effa EN, Starkey MP, Telfer P, Thibault M, Tutin CEG, White LJT \& Wilkie DS. 2003. Catastrophic ape decline in western equatorial Africa. Nature. 422: 611-614.

[18] WTG (Watershed Task Group), 2008. Annual Report Dizangue, Cameroon. 